\section{Impact of Fungal Gummosis on Peach Trees}

\author{
T.G. Beckman ${ }^{1}$ \\ U.S. Department of Agriculture, Agricultural Research Service, Southeastern \\ Fruit and Tree Nut Research Laboratory, 21 Dunbar Road, Byron, GA 31008
}

P.L. Pusey ${ }^{2}$

U.S. Department of Agriculture, Agricultural Research Service, Tree Fruit Research Laboratory, 1104 N. Western Avenue, Wenatchee, WA 98801.

\section{P.F. Bertrand ${ }^{3}$}

University of Georgia, Rural Development Center, 15 RDC Road, Tifton, GA 31793

Additional index words. Botryosphaeria dothidea, peach fungal gummosis, blister canker, Prunus persica, captan, captafol

\begin{abstract}
Peach tree fungal gummosis caused by Botryosphaeria dothidea [(Moug.:Fr.) Cos \& de Not.] is widespread throughout the southeastern United States. Until recently, its economic impact on peach [Prunus persica (L.) Batsch] has been impossible to estimate, since no effective controls were known. Significant, though not total, suppression of gummosis on 'Summergold' peach trees was achieved with an intensive 5-year spray program with captafol. Captan was far less effective than captafol. Both trunk diameter and fruit yield were negatively correlated with disease severity. After eight growing seasons, trees treated with captafol were $18 \%$ larger than the untreated trees. Yield of mature captafol-treated trees was $40 \%$ to $60 \%$ higher than that of untreated ones. Following termination of the spray program after 5 years, disease severity gradually increased on both captafol- and captan-treated trees. However, through eight growing seasons, disease severity was significantly lower on captafol-treated trees. This study demonstrates that peach tree fungal gummosis significantly depresses tree growth and fruit yield on susceptible peach cultivars.
\end{abstract}

Peach tree fungal gummosis first appeared in Georgia during the 1960s. The disease is characterized by numerous gum extrusions on trunks, limbs, branches, and twigs. Symptoms include sunken lesions around lenticels and blisters on surfaces of shoots and twigs. Severely affected trees exude large amounts of gum from these lesions, especially following extended periods of rainfall. Infected trees are weakened, exhibiting dieback of twigs, shoots, and even limbs. Trees may die during prolonged stress periods (Daniell and Chandler, 1982; Weaver, 1974). The causal agent has been identified as Botryosphaeria dothidea (Weaver, 1974). Since that time, it has spread throughout the southeastern U.S. peach production areas (Pusey et al., 1986; Reilly and Okie, 1982). Scientists and growers alike feared it would be the end of the peach industry if fungal gummosis was not controlled (Reilly and Okie, 1982; Weaver, 1976). Despite its dramatic appearance, many growers have come to regard it as a nuisance that can be "pruned out" of trees during the dormant season and is of no economic significance other than increased pruning costs. However, literature lacks data to support this position.

Received for publication 15 July 2002. Accepted for publication 31 Dec. 2002. We express our gratitude to Kathy Halat, Raymon Pate, and Sean Bertrand for their help and support in this experiment.

${ }^{1}$ Research Horticulturist.

${ }^{2}$ Research Pathologist.

${ }^{3}$ Extension Pathologist.
Aside from detailed pruning to remove infected wood and flail mowing to speed decomposition of infected prunings that would otherwise serve as a source of inoculum, there are no recommendations for the management or control of this disease in the Southeast. However, Pusey and Okie (1994) demonstrated that an intensive spray program with fungicides might provide effective control of gummosis, thus making it feasible to study the economic impact of this problem. The purpose of this project was to determine the effect of peach fungal gummosis on growth and fruit yield of peach.

\section{Materials and Methods}

Trees of 'Summergold'/'Lovell' peach were planted in Feb. 1990 at a spacing of 6.1 $\times 6.1 \mathrm{~m}$ at the Southeastern Fruit and Tree Nut Research Laboratory, Byron, Ga. Experimental plots were established in a randomized complete-block design with 10 three-tree replicates of each fungicide treatment (row $=$ block). Trees were maintained according to standard commercial recommendations (Myers, 1989), and they received no supplemental irrigation. 'Summergold' was selected as the scion cultivar because of its known susceptibility to gummosis (Britton et al., 1990).

Work by several researchers (Pusey, 1989a; Pusey et al., 1985; Weaver, 1979) indicated that airborne ascospores or through rainsplash from nearby infected trees. Therefore, 'Redglobe' inoculum may enter a new orchard either as trees of the previous orchard were left intact to provide an inoculum source. The experimental block was surrounded by severely diseased 15-year-old 'Redglobe' peach trees (two rows on each side).

Experimental fungicidal treatments are outlined in Table 1. With the exception of Whiton powder, fungicide treatments commenced $30 \mathrm{~d}$ postbloom (typically mid-late April) and were repeated at 2-week intervals for a total of 8-10 treatments each year. Each spray was applied to the trunk and scaffold limbs to runoff. Whiton powder was applied to the trunks and scaffolds once annually prior to budbreak. An additional control treatment differed from the water control in that Botryosphaeria-infected prunings were placed in the canopy each spring to provide additional inoculum pressure. Infected prunings were prepared by spraying peach prunings to runoff with a spore suspension of $B$. dothidea $\left(10^{5}\right.$ spores $\left./ \mathrm{mL}\right)$. Isolate was a known virulent strain (PI-5) collected from peach in Georgia (Pusey, 1989b; Pusey et al., 1986). Following inoculation, prunings were piled for at least a 3-week period at the edge of a wooded area before use. Treatments were applied from 1990 through 1994 during each growing season and were then suspended thereafter to determine whether the disease suppression achieved would persist in the absence of a spray program. This decision was based on the apparent relationship between bark age and disease susceptibility. Weaver (1979) artificially inoculated peach bark varying in age from 1- to 3-years-old and noted reduced symptom expression on the older bark. Similarly, in an orchard study to determine when peach trees were infected, it was noted that the portion of the trunk of peach trees that had been protected with covers for the first 2 years following planting were still essentially free of gummosis at 5 years of age; unprotected portions displayed severe symptoms (Pusey and Bertrand, 1993; Pusey and Okie, 1994). Hence, it appeared possible that control of fungal gummosis might be necessary only during the first few years following orchard establishment.

Each fall, trunk diameter was measured $30 \mathrm{~cm}$ above the soil line. Previous work had demonstrated that symptom development following inoculation required 12-18 months (Pusey, 1993; Pusey et al., 1986; Weaver, 1974). Therefore, starting in Fall 1991, tree trunks and scaffolds were evaluated for gummosis severity using the rating scale shown in Table 2. Disease ratings were based on visual observation of the trunk and the main scaffold

Table 1. Fungicide spray treatments (1990-94, Byron, Ga.).

\begin{tabular}{lc}
\hline Fungicide & Application rate \\
\hline 1. Captafol 80WP & $4.8 \mathrm{~g} \cdot \mathrm{L}^{-1}$ \\
2. Captan 50WP & $3.0 \mathrm{~g} \cdot \mathrm{L}^{-1}$ \\
3. Tenn-copp 5E & $6.3 \mathrm{~mL} \cdot \mathrm{L}^{-1}$ \\
4. Whiton powder + & $333 \mathrm{~g} \cdot \mathrm{L}^{-1}$ \\
tribasic copper sulfate 53 WP & $8.7 \mathrm{~g} \cdot \mathrm{L}^{-1}$ \\
5. Control & --- \\
6. Control + & --- \\
B. dothidea infected prunings & -- \\
\hline
\end{tabular}
${ }^{2} 98.5 \%$ calcium carbonate, Shiraishi Calcium Kaisha, Japan. 
Table 2. Rating scale used to evaluate trunk and scaffold gummosis (1991-97, Byron, Ga.).

\begin{tabular}{ll}
\hline Rating & \multicolumn{1}{c}{ Description } \\
\hline 0 & No gum sites \\
1 & 1 or 2 gum sites or lesions on trunk or \\
& scaffolds \\
2 & $3-10$ gum sites or lesions on trunk or \\
& scaffolds \\
3 & $11-25$ gum sites on trunk or scaffolds \\
4 & 26-50 gum sites on trunk or scaffolds \\
5 & 51 or more gum sites on trunk or \\
& scaffolds \\
\hline
\end{tabular}

limbs only. The fruit crop was harvested in the years from 1992 to 1994 . In order to reduce management costs, the experimental plan had been to cease collecting fruit yield data and only monitor disease severity following conclusion of fungicide treatments in 1994. However, due to the marked increase in disease severity on the captafol-treated trees following cessation of fungicide treatments, an additional fruit harvest was performed in 1997 to determine impact of disease severity on fruit yield. No attempt was made to sort cullage; hence, weights reported are total gross yields.

Data were analyzed by the General Linear Models (GLM) program of the Statistical Analysis System for personal computer (SAS Institute, Cary, N.C.). Mean separation was performed by least significant differences (LSD).

\section{Results and Discussion}

Expression of disease symptom was very rapid in the control treatments (Table 3), probably aided by high inoculum levels provided by the heavily infected 'Redglobe' peach trees that surrounded this experimental planting. Infection in the control treatment that had been augmented with infected prunings was only briefly more severe than that in the water control without prunings. Both control treatments subsequently reached the maximum rating of gummosis. Infection and symptom expression were more rapid than expected, and the rating scale was not wide enough to capture visible differences among the most severely afflicted trees. Through 1992 neither the tenn-copp nor whiton powder treatments showed any observable effect on gummosis compared to controls; therefore, data collection for these treatments was terminated.

Gummosis severity gradually increased in all treatments through the end of this study in 1997. Both the captan and captafol treatments lagged markedly behind the controls in symptom expression. However, gummosis gradually increased in the captan treatment and in 1995, one year after all fungicide treatments were terminated, was not significantly different from the controls. Captafol provided significant symptom suppression throughout the course of this study. Results indicated that while it may be possible to reduce symptom expression significantly with an intensive spray program during the first 5 years following planting, it was not possible to suppress symptoms totally with the fungicides tested. Thus, a continued disease-management program may be necessary throughout the life of an orchard.

Table 3. Effect of fungicide treatments on the gummosis ratings ${ }^{z}$ of 'Summergold' peach (1991-97, Byron, Ga.).

\begin{tabular}{lccccccr}
\hline & \multicolumn{8}{c}{ Gummosis rating } \\
\cline { 2 - 8 } Fungicide & 1991 & 1992 & 1993 & 1994 & 1995 & 1996 & 1997 \\
\hline Control & 2.4 & 3.4 & 4.5 & 4.9 & 4.8 & 5.0 & 4.9 \\
Control + prunings & 2.1 & 3.8 & 4.6 & 5.0 & 4.8 & 5.0 & 5.0 \\
Tenn-copp & 2.3 & 3.6 & --- & --- & --- & --- & -- \\
Whiton + Cu & 1.6 & 3.3 & -- & --- & --- & -- & -- \\
Captan & 0.5 & 1.1 & 3.6 & 4.5 & 4.6 & 4.8 & 4.6 \\
Captafol & 0.1 & 0.2 & 1.2 & 2.3 & 2.4 & 3.1 & 3.1 \\
LSD $_{0.05}$ & 0.6 & 0.4 & 0.4 & 0.3 & 0.6 & 0.3 & 0.3 \\
\hline
\end{tabular}

${ }^{2}$ Rating scale of $0-5$ (Table 2).

Table 4. Effect of fungicide treatments on trunk cross-sectional area of 'Summergold' peach (1991-97, Byron, Ga.).

\begin{tabular}{lccccccc}
\hline & \multicolumn{7}{c}{ Trunk cross-sectional area $\left(\mathrm{cm}^{2}\right)$} \\
\cline { 2 - 8 } Fungicide & 1991 & 1992 & 1993 & 1994 & 1995 & 1996 & 1997 \\
\hline Control & 28.3 & 52.5 & 69.0 & 92.7 & 103.6 & 122.8 & 126.4 \\
Control + prunings & 26.5 & 51.6 & 66.7 & 93.3 & 103.9 & 123.7 & 125.8 \\
Tenn-copp & 27.0 & 52.6 & --- & --- & --- & --- & --- \\
Whiton + Cu & 28.4 & 53.2 & --- & -- & --- & --- & --- \\
Captan & 28.0 & 48.9 & 68.2 & 93.7 & 102.5 & 115.4 & 131.3 \\
Captafol & 30.9 & 59.7 & 78.8 & 111.2 & 120.8 & 139.2 & 149.4 \\
LSD $_{0.05}$ & 3.4 & 5.8 & 7.7 & 11.4 & 12.8 & 15.1 & 18.7 \\
\hline
\end{tabular}

Table 5. Effect of fungicide treatments on fruit yield of 'Summergold' peach (1992-94 and1997, Byron, $\mathrm{Ga}$.).

\begin{tabular}{|c|c|c|c|c|c|c|}
\hline \multirow[b]{3}{*}{ Fungicide } & \multicolumn{6}{|c|}{ Total fruit yield (kg/tree) } \\
\hline & & & & Cumulative & & Cumulative \\
\hline & 1992 & 1993 & 1994 & 1992-94 & 1997 & $1992-94+1997$ \\
\hline Control & 10.3 & 16.6 & 41.7 & 68.6 & 23.7 & 88.2 \\
\hline Control + prunings & 13.7 & 15.6 & 44.1 & 71.5 & 23.0 & 91.5 \\
\hline Tenn-copp & 12.3 & --- & --- & --- & --- & --- \\
\hline Whiton + $\mathrm{Cu}$ & 10.7 & --- & --- & --- & --- & --- \\
\hline Captan & 12.2 & 17.9 & 48.1 & 78.1 & 24.1 & 95.8 \\
\hline Captafol & 11.7 & 12.5 & 58.5 & 82.7 & 39.1 & 119.1 \\
\hline $\mathrm{LSD}_{0.05}$ & 5.2 & 2.8 & 8.7 & 11.2 & 9.2 & 18.0 \\
\hline
\end{tabular}

Tree growth as expressed by trunk crosssectional area was not correlated initially with disease severity. However, from 1993 through the end of this study, tree growth displayed a significant negative correlation with disease severity each year ranging from $\mathrm{r}=-0.18$ to $-0.29(P<0.05)$. Captafol-treated trees were larger than those in other treatments throughout the course of this study (Table 4). At the conclusion of this study covering eight growing seasons, captafol-treated trees were $18 \%$ larger than trees in the water control treatment.

Fruit yield of captafol-treated trees recovered from a slow start and overtook all other treatments in 1994 and 1997, resulting in the highest cumulative yields through 1994 or when 1997 yield was included (Table 5). This result can be attributed to both the significant size advantage of captafol-treated trees throughout this study and also to their higher yield efficiency in 1997 (Table 6). Compared to the water control treatment, captafol-treated trees provided a $40 \%$ and $64 \%$ increase in yield in 1994 and 1997, respectively. In 1994 and 1997, the 2 years with greatest production, yield was negatively correlated with symptom severity $(\mathrm{r}=-0.38$ and $\mathrm{r}=-0.27$, respectively, $P<0.0001)$.

Overall, captafol-treated trees performed markedly better than trees in all other treatments in this study. This is only partially reflected in the symptom ratings since the scale was not
Table 6. Effect of fungicide treatments on yield efficiency of 'Summergold' peach (1992-1994 and 1997, Byron, Ga.).

\begin{tabular}{lcccc}
\hline & \multicolumn{4}{c}{ Yield efficiency $\left(\mathrm{kg} \cdot \mathrm{cm}^{-2}\right)$} \\
\cline { 2 - 5 } Fungicide & 1992 & 1993 & 1994 & 1997 \\
\hline Control & 0.20 & 0.25 & 0.46 & 0.20 \\
Control + prunings & 0.28 & 0.23 & 0.48 & 0.20 \\
Tenn-copp & 0.24 & --- & --- & --- \\
Whiton + Cu & 0.20 & - & --- & --- \\
Captan & 0.27 & 0.27 & 0.54 & 0.23 \\
Captafol & 0.20 & 0.16 & 0.54 & 0.27 \\
LSD $_{0.05}$ & 0.11 & 0.03 & 0.07 & 0.05 \\
\hline
\end{tabular}

wide enough to capture differences that could be distinguished by visual observation. Also not reflected in these ratings is the significant twig and branch dieback exhibited by severely afflicted trees. It was our observation that this dead material could not be pruned out each dormant season without reducing bearing canopy volume. Estimates of the impact of fungal gummosis on the horticultural performance of peach trees are obviously conservative since symptom suppression was imperfect with the best fungicide treatment used. Unfortunately, captafol is no longer registered for use on peach, and captan did not provide sustained suppression or control of the disease even when applied 8-10 times each season in this experiment. At this time there is no chemical control for fungal gummosis of peach. 
Although a few resistant peach lines have been identified (Okie and Pusey, 1996), most of these are "exotic" lines, lacking cultivar quality. Hence, at best, it likely will take several generations before adapted resistant cultivars could become available. Nonetheless, in light of the negative impact of gummosis on tree growth and fruit yield found in this study and the current absence of a proven cost-effective chemical control or management strategy, genetic resistance is a goal worth pursuing. This is especially so given the questionable costeffectiveness and longevity of any chemical control program developed in the future if it requires a spray application frequency approaching that used in this trial.

In the interim, growers will have to rely on current orchard management practices, hopefully augmented with a chemical control. Taylor and Sherman (1997) recently demonstrated the efficacy of phosphorous acids in providing at least partial suppression of gummosis under field conditions. We recently tested a range of registered fungicides and found several that provided significant suppression of Botryosphaeria dothidea in vitro (Beckman et al., 1999). The most promising of these are currently under trial to determine their efficacy in the orchard.

\section{Literature Cited}

Beckman, T.G., C.C. Reilly, and M. Shah. 1999. Evaluation of fungicides for control of peach tree fungal gummosis. Fungicide and Nematicide Tests 54:54-55.

Britton, K.O., F.F. Hendrix, P.L. Pusey, W.R. Okie, C.C. Reilly, and J.W. Daniell. 1990. Evaluating the reaction of peach cultivars to infection by three Botryosphaeria species. HortScience 25: 468-470.

Daniell, J.W. and W.A. Chandler. 1982. Field resistance of peach cultivars to gummosis disease. HortScience 17:375-376.

Myers, S.C. 1989. Peach production handbook. Georgia Ext. Hdbk. No. 1. Coop. Ext. Serv., Univ. of Georgia, Athens.

Okie, W.R. and P.L. Pusey. 1996. USDA peach breeding in Georgia: Current status and breeding for resistance to Botryosphaeria. Acta Hort. 374:151-158.

Pusey, P.L. 1989a. Availability and dispersal of ascospores and conidia of Botryosphaeria in peach orchards. Phytopathology 79:635-639.

Pusey, P.L. 1989b. Influence of water stress on susceptibility of nonwounded peach bark to Botryosphaeria dothidea. Plant Dis. 73: 1000-1003.

Pusey, P.L. 1993. Role of Botryosphaeria species in peach tree gummosis on the basis of differential isolation from outer and inner bark. Plant Dis. 77:170-174.
Pusey, P.L. and P.F. Bertrand. 1993. Seasonal infection of nonwounded peach bark by Botryosphaeria dothidea. Phytopathology 83:825-829.

Pusey, P.L. and W.R. Okie. 1994. Update on peach tree fungal gummosis in the Southeast, $\mathrm{p}$. 49-58. Proc. 6th Stone Fruit Decline Wkshp., 26-28 Oct. 1992, Fort Valley State College, Ft. Valley, Ga.

Pusey, P.L., C.C. Reilly, and W.R. Okie. 1985. Peach tree fungal gummosis, p. 151-160. Stone Fruit Tree Decline Wkshp. Proc., 30 Oct.-1 Nov. 1984. Appalachian Fruit Res. Stn., Kearneysville, W.Va.

Pusey, P.L., C.C. Reilly, and W.R. Okie. 1986. Symptomatic responses of peach trees to various isolates of Botryosphaeria dothidea. Plant Dis. 70:568-572.

Reilly, C.C. and W.R. Okie. 1982. Distribution in the southeastern United States of peach tree fungal gummosis caused by Botryosphaeria dothidea. Plant Dis. 66:158-161.

Taylor, J.B. and W.B. Sherman. 1997. Foliar applied phosphorous fertilizers inhibit peach gummosis. Proc. Fla. State Hort. Soc. 110:182-183.

Weaver, D.J. 1974. A gummosis disease of peach trees caused by Botryosphaeria dothidea. Phytopathology 64:1429-1432.

Weaver, D.J. 1976. Peach tree gummosis-A serious new disease. Fruit South 1:4-5.

Weaver, D.J. 1979. Role of conidia of Botryosphaeria dothidea in the natural spread of peach tree gummosis. Phytopathology 64:330-334. 